\title{
Monitoring of Organophosphorus Pesticides in Brazilian Food
}

\author{
Tatiana SM Fernandes* and Ronaldo F Nascimento \\ Department of Analytical Chemistry and Physical Chemistry, Federal University of Ceará, Brazil
}

*Corresponding author: Tatiana SM Fernandes, Research at Laboratório de Análises de Traços, Fortaleza, Fortaleza, Ceará, Brazil.

To Cite This Article: Tatiana SM Fernandes, Ronaldo F Nascimento. Monitoring of Organophosphorus Pesticides in Brazilian Food. Am J Biomed Sci \& Res. 2019 - 4(2). AJBSR.MS.ID.000769. DOI: 10.34297/AJBSR.2019.04.000769

Received: July 08, 2019 | Published: July 22, 2019

\begin{abstract}
The accumulation of agrochemicals in agricultural products is a major concern since the plants act as intermediates in the transport of soil, water, and air contaminants to humans and fauna. The assessment of pesticide residues in food has become a priority objective, ensuring the quality of food and protecting consumers against possible risks. Brazil has legislation on pesticides, but monitoring is still far from other countries, as is the case in the USA and Europe. Therefore, it is necessary to establish better practices for the evaluation of pesticide residues in food.
\end{abstract}

\section{Introduction}

The monitoring of pesticides in the environment is a very important tool in the characterization and management of environmental risks resulting from the use of these products under real conditions [1], as well as a form of measurement in minimizing the potential risk of contamination by pesticides in humans [1,2] and to assist in compliance with legislation [3]. According to the Brazilian Federal Decree No. 4,074 of 2002, the monitoring of pesticides can also be part of the evaluation process in the registration of new products, or yet the re-evaluation of products in use [4].

The monitoring and evaluation of the impacts in the use of pesticides should be seen as vital activities, ensuring the sustainability of the agricultural production systems that use pesticides, in addition to ensuring compliance with regulations [5], to assure that the applications of pesticides be made according to the proposed good agricultural practices (GAP) [5-7], resulting in a safe product for the consumer [6,8]. If GAP is applied efficiently, the number of pesticide residues will be below the corresponding to the maximum residue level [8]. The monitoring of pesticide residues acts as an essential practice in guaranteeing food safety [7$11]$ and preventing contamination through the food chain $[10,11]$. According to Masiá et al. [3]. There are three important pillars in legislation to ensure the pesticide and veterinary drug residues control through the food chain:

a. Authorized Products, b. Maximum Residue Limits (MRLs) and

c. Analytical Methods' Guidelines.

Both the government and the private sector have come to attach greater importance to the analysis of pesticide residues, where there is increasing pressure to improve analytical performance, requiring increased efficiency by reducing the cost and time of analyzes [12]. Monitoring of chemical residues in food is necessary to ensure that human exposure to pesticides $[1,2,12,13]$, mainly through dietary intake, does not exceed tolerable levels [13]. According to WHO, on average, $30 \%$ of the diet consists of fruits and vegetables $[14,15]$, being consumed mainly raw or semi-processed [14], and consequently, they are expected to contain higher levels of pesticide residues [14-16] in comparison with other food groups of animal origin [15]. It is impossible to eliminate pesticide residues from the vegetables' internal parts, due to the pesticide's ability to penetrate inside of the leaves and pulps $[17,18]$.

A prerequisite for obtaining high-quality results in a monitoring and surveillance program is the development of sensitive $[16,19,20]$, selective, and reproducible analytical methods and techniques [19]. The analytical methodologies should accurately identify and quantify the concentration of any substance, generally at very low levels, to control and monitor pesticide residues [21], and they should be able to determine the number of possible compounds in an analysis, where multi-residue methods have become more popular because they can determine a wide range of compounds [22]. 
In a joint initiative, FAO and WHO created the Codex Alimentarius through expert groups that established the Acceptable Daily Intake (ADI) and MRLs for each pesticide, where Codex Alimentarius has so far established MRLs for some 218 pesticides (and for numerous combinations of pesticides/commodities) available in a public database [3]. Thus, in establishing programs to monitor pesticide residues in food for several consecutive years, it is possible to know the profile of existing residues, and thus to promote quality assurance, focusing on the education of farmers, control of the sale of agrochemicals, integrated management of pests and increase of organic agriculture [23].

Many countries routinely carry out pesticide residue management programs on vegetal and animal origin, cereal grains and baby foods $[23,24]$, where each country determines its form of monitoring $[25,26]$. The food monitoring programs implemented in Brazil are carried out by the Ministry of Agriculture and Livestock and Supply (MAPA), and the Ministry of Health through the National Agency of Sanitary Surveillance (ANVISA) [23], and have been implemented since 2001 with the objective to evaluate food quality and implement actions to control pesticide residues $[27,28]$. There are currently two monitoring of residues of pesticides in food of plant origin, with the objective of evaluating compliance with national MRLs: National Plan for the Control of Residues and Contaminants in Products of Vegetable Origin (PNCRC/VEGETAL) [29], coordinated by MAPA and the Program on Pesticide Residue Analysis in Food (PARA), coordinated by ANVISA [14,27]. Among the two, the PARA is the one that has the greatest coverage both in the states (including Ceará) and in the analyzes, quantities, and types of samples analyzed [23,27].

However, when compared to international control programs, the PARA in Brazil does not estimate the reality of chronic exposure due to consumption, not generating consistent data for comparison over a period [23]. The summary of the results of the PARA on the ANVISA website is periodically published $[27,30]$, and those of the PNCRC are published in the official government daily (DOU) [27,31].

\section{Multi-Residue Methods}

Due to many pesticides on the market, the use of methods capable of analyzing many agrochemicals in a single analysis is currently the most common approach [32-36]. In the multiresidue method, different active ingredients of pesticides are simultaneously analyzed in the same sample, being able to detect several metabolites [37].

In the last decades, the analysis of pesticide residues, with significant analytical developments, was well achieved, in many cases; the sample preparation and analytical detection were the focus, this has allowed MRLs to become increasingly stringent in food products [9]. The development of multi-residue methods allowed the analysis of a large number of substances with a high percentage of recovery (accuracy) of the analytes and the removal of the possible interferents of the sample, besides good precision, robustness, reduction of technical work and the use of solvents $[12,38,39]$.
In recent years, the tendency has been for analytical methods to become faster [40-42] and simple [40,41], but at the same time detect lower levels $[40,41,43]$, besides being more sensitive $[41,43]$ and more accurate in the identification and quantification of analytes in complex matrices (e.g. food products) and that are reliable [41]. The use of multi-residue methods emerges as a more common and efficient way of performing pesticide residue analyses on hundreds of different compounds, and it is possible to measure a range of MRLs of 0.01 to 10 mg.kg-1 [33]. The multi-residue method is the most recognized and used technique for monitoring pesticide residues in food, being adopted by countries such as Germany, Australia, Canada, the United States, the Netherlands, among others $[17,18,37]$.

Both sample preparation and calibration strategies are important aspects that should be considered in multi-residue methods, in order to determine recommendations that balance data quality, as well as time and financial investments [40]. Rapid multiresidue analysis methods are essential to simplify and minimize the costs of sample preparation [42,44] by reducing consumables and waste generated [44]. The multi-residue method favors rapid and efficient monitoring $[17,18,37]$, due to the increase in laboratory productivity $[17,18,37,45]$ by significantly reducing the analysis time, reducing costs [37].

The diverse nature and structure of pesticides require different pretreatment approaches by increasing the work of analysis and decreasing laboratory productivity [46]. Thus, in some cases, it is still necessary to develop simple residue methods for the analysis of a pesticide or some pesticides from the same chemical family [33]. The QuEChERS method changed the mode of multi-residue analysis [41,47-50], as it proved suitable for large-scale residue analyzes in a broad variety of matrices $[41,44,47]$, ensuring exact results, accurate and low detection limits for a wide variety of compounds $[50,51]$. This pretreatment method is very flexible [52,53] and extensively applied in the determination of various pesticide residues in agricultural products $[35,46,52,54-56]$. There is a need to develop rapid methods for multi- residue determination of the most commonly used pesticides to monitor pesticide residues in food and ensure not only food safety but also compliance with GAP $[7,52]$.

\section{Maximum Residue Limits (MRLs)}

Different guidelines have been established around the world, restricting the pesticide residues in food, as a way to ensure the safe consumption of food by the population[24,46,57,58], so governments and agencies fixed MRLs [2,8, 4,50,57-60], that are specified by each country's federal legislation for each analyte and matrix $[62,63]$. The legislation also establishes the interval of the safety of each active pesticide ingredient for each crop [61].

The MRL is the maximum amount of pesticide or related residues (metabolites and coadjutants) that remains officially in food, due to the correct application in a specific phase, from its production to consumption $[2,3,14,23,61]$. Therefore, MRL values represent the maximum concentration of pesticide residue that is legally allowed 
in food products $[2,64]$, and thus, can be legally marketed. The MRL is expressed in parts of the pesticide (by weight), or their residues per million parts of feed (by weight) (ppm or mg.kg-1) [4].

MRLs limit the types and amount of pesticides that may be legally present in food, according to standards set by various regulatory bodies, to minimize consumer exposure to harmful or unnecessary pesticide ingestion around the world $[2,61,64]$, as well as promoting BPA in the use of pesticides [64]. MRLs are not toxicological limits because they do not represent the maximum amount of active substances that can harm the health of consumers [14]. For the MRL of a certain active ingredient in a food to be correctly established, in addition to the proposed safety interval, it is necessary to take into account the soil and climatic conditions, pests present in the environment, indications of dose and form of application, and this set of factors called GAP [65]. For a product and similar products in the country that there are no limits established, the MRLs by the Codex Alimentarius are used [23]. After demonstrating that the residues are safe for consumers, and based on the rigorous assessment of each legally authorized pesticide [3], the MRLs are established for each pesticide and required for each food crop, taking into account the ADI [65], being the MRL used as the basis for the calculation of exposure and food risk assessment [23].

In Brazil, ANVISA is responsible for establishing MRLs $[61,63,66,67]$ by using toxicity data from each compound $[14,23,63]$, but only natural vegetable crops (in natura) MRLs are established [67]. Each one of the active ingredients with authorized use in Brazil has its respective monograph containing a compilation of information (common name, chemical name, use class, toxicological classification, authorized agricultural crops, and MRLs in force) [30]. For Lemos et al. [14] a value above the MRL of a pesticide does not necessarily imply that there is a health risk, which could be assessed by other parameters such as the ADI. Lemos et al. [14] warn that in a study with statistically significant samples, many samples exceeding the MRL may indicate a potential health risk and need for health risk assessment. Thus, analytical methodologies for the determination of toxic substances in food should be able to quantify residues at very low concentrations, as well as to identify them unequivocally, ensuring that the MRLs are respected [24].

\section{Acceptable Daily Intake (ADI)}

The ADI is a safety parameter used to establish the MRLs $[23,37,65,68]$. The ADI is the maximum amount that is taken daily throughout life, does not present a significant health risk compared to current knowledge, and it is expressed in milligram (mg) of the pesticide per kilogram (kg) of body weight (mg kg-1 b.w.) $[37,65]$. It is obtained using toxicological studies [23].

In the same way as the MRLs, the ADI is stipulated for each pesticide, based on studies of the pesticide's physicochemical, metabolic, pharmacological and toxicological properties of pesticides $[37,65]$ from laboratory animal studies and performed with procedures recognized at the international level [65]. In
Brazil, ANVISA is the agency responsible for establishing the ADI of each pesticide active ingredient for each crop [66]. In Brazil, the ANVISA website provides the IDA values from the authorized monographs of each active ingredient (IA) [30], already the values in the international scope $[69,70,71]$ can be obtained from their respective websites $[69,70,71]$.

In a study conducted by Gerage [72], in the Northeast region, of the 283 pesticides considered in the research, 62 compounds exceeded the IDA value established by ANVISA, among these compounds the OPPs chlorpyrifos and disulfoton was found. In another research done by Meira [73], in schools in São Paulo, in which of the 272 pesticides studied, nine were above the IDA by ANVISA (most were very toxic), with four compounds in the organophosphorus (OPPs) group (acephate, diazinon, pirimiphosmethyl, and terbufos). The toxic effect of a pesticide can be potentiated in view of the simultaneous exposure to other pesticide residues that have the same toxic action mechanism, being necessary to take into account the exposure to multiple residues of pesticides present in the different foods eaten during a meal, during the day or throughout life [37].

\section{Program on Pesticide Residue Analysis in Food (PARA)}

The strict inspection of residues in food by appropriate state agencies or other institutions is considered of great importance, since pesticides are one of the most dangerous groups of chemical compounds, due to their toxic properties, persistence in the environment, and ability to bioaccumulate [74]. With the objective of structuring a service to evaluate food quality and implement waste control actions, in 2001 the Project for the Analysis of Pesticide Residues in Foods was developed, which became a program through the Resolution of the Collegiate Board of Directors - RDC no 119 of May 19, 2003, and was developed annually under the National Health Surveillance System (SNVS) $[17,18,37,75]$.

The creation of the PARA allowed the country to have a clearer understanding of the levels of pesticides present in its agricultural products [76]. According to the PARA of 2016 [37], the program counts on the participation of 27 Federative Units involved in the sampling and taking of actions after the dissemination of the results, where the analyzes are carried out by four Central Public Health Laboratories and by a private laboratory contracted by bidding process.

The PARA periodically monitors various in natural foods by investigating the presence of pesticides, and thus promoting the health of the Brazilian population [66]. It is possible with PARA to verify if foods commercialized in retail have levels of pesticide residues within the MRLs established by ANVISA published in a monograph specific to each pesticide by checking whether the pesticides used are properly registered in the country, and have been applied only to the crops for which they were authorized $[17,18]$, besides estimating the exposure of the population to pesticide residues in plant foods and, consequently, assess the health risk of such exposure [18]. In this way, the PARA helps food safety [18,37], preventing acute or chronic intoxications that may 
arise from undue dietary exposure to pesticides [18,61], making it possible to diagnose the use of pesticides in foods of plant origin covered by the program $[17,18]$.

The choice of food monitored by PARA is based on the consumption data obtained in the Consumer Expenditure Survey (POF) $[17,18,23,37]$ performed by the IBGE [37], the availability of food in the supermarkets of the different units of the Federation $[17,18,37]$, and in pesticides with the highest detection rate in food [37]. The sampling schedule is approved in advance by during the national meetings of the PARA $[17,18,37]$. Brazil is at the top of the use of pesticides, mainly in the production of commodities. The PARAs confirm residues of unapproved substances are found in foods consumed daily by the Brazilian population and in amounts greater than those approved by law [23,27]. The PARA also shows that the use of banned pesticides in Brazil persists, such as chlorpyrifos $[17,37,75,77]$. A factor to be considered is that residues of some non-recommended and restricted-use pesticides can also be found in fruits and vegetables due to indirect sources such as adjacent crops, soil and irrigation water [78]. The PARA recommends that consumers purchase certified and traceable food to farmers and adopt GAPs to reduce the consumption of pesticide residues and prevent health damage $[17,18,37]$.

In the extraction of pesticides, the Mini-Luke modified and QuEChERS methods have been used. The analytical method of multi-residues or specific methodologies previously validated is applied for sample analysis [37]. According to the PARA of 2016 [37], of the irregular detections per chemical group, the analyzed samples that presented pesticides from the OPPs group, of the 4,824 studied, 3,088 were regular and 1,736 irregulars, representing $35.98 \%$ detections. The bell pepper has presented a high index of unsatisfactory results, with samples containing pesticides not authorized for culture, where the presence of organophosphates was verified $[17,37,75,77,79]$. Of the three pesticides with the highest number of irregular detections in the last PARA (2016), two were organophosphates (acephate and chlorpyrifos). Grape was the sample with the highest number of irregular detections with acephate (pesticide detected in 18 of the 25 monitored foods), while tomato sample presents mostly chlorpyrifos (its use is not authorized for this crop) [37].

\section{References}

1. ICSF Jardim, JÁ Andrade, SCN Queiroz (2009) Resíduos de agrotóxicos em alimentos: uma preocupação ambiental global - um enfoque às maçãs. Quím Nova 32(4): 996-1012.

2. GT Bakırcl, DBY Acay, F Bakırcı, S Ötleș (2014) Pesticide residues in fruits and vegetables from the Aegean region, Turkey. Food Chem 160(1): 379392.

3. A Masiá, MM Suarez-Varela, A Llopis-Gonzalez, Y Pico (2016) Determination of pesticides and veterinary drug residues in food by liquid chromatography-mass spectrometry: A review. Analytica Chimica Acta 936(14): 40-61.

4. Decreto Federal no 4.074, de 04 de Janeiro de 2002. Brasília, DF, 082002. Seção, Brazil. (1). 1.

5. GK Blankson, P Osei-Fosu, EA Adeendze, D Ashie (2016) Contamination levels of organophosphorus and synthetic pyrethroid pesticides in vegetables marketed in Accra, Ghana. Food Control 68: 174-180.
6. T Portolés, JGJ Mol, JV Sancho, FJ López, F Hernández (2014) Validation of a qualitative screening method for pesticides in fruits and vegetables by gas chromatography quadrupole-time of flight mass spectrometry with atmospheric pressure chemical ionization. Anal Chim Acta 838(1): 76-85.

7. LDC Cabrera, SS Caldas, OD Prestes, EG Primel, R Zanella (2016) Evaluation of alternative sorbents for dispersive solid-phase extraction clean-up in the QuEChERS method for the determination of pesticide residues in rice by liquid chromatography with tandem mass spectrometry. J Sep Sci 39(10): 1945-1954.

8. SW Chung (2018) How effective are common household preparations on removing pesticide residues from fruit and vegetables? A review. J Sci Food Agric 98(8): 2857-2870.

9. M Jokanović (2012) The Impact of Pesticides. 1a ed. AcademyPublish. $\operatorname{org} \circledast$, USA.

10. A Melo, SC Cunha, C Mansilha, An Aguiar, O Pinho, etal. (2012) Monitoring pesticide residues in greenhouse tomato by combining acetonitrilebased extraction with dispersive liquid-liquid microextraction followed by gas-chromatography- mass spectrometry. Food Chem 135(3): 10711077

11. NC Muñoz, L Floriano, MP Souza, NM Bandeira, OD Prestes, et al. (2017) Determination of pesticide residues in golden berry (Physalis peruviana L) by modified QuEChERS method and ultra-high-performance liquid chromatography-tandem quadrupole mass spectrometry. Food Analytical Methods 10(2): 320-329.

12. OD Prestes, CA Friggi, MB Adaime, R Zanella (2009) QuEChERSum método moderno de preparo de amostra para determinação multirresíduo de pesticidas em alimentos por métodos cromatográficos acoplados à espectrometria de massas. Química Nova 32(6): 1620-1634.

13. LM Chiesa, GF Labella, A Giorgi, S Panseri, R Pavlovic, et al. (2016) The occurrence of pesticides and persistent organic pollutants in Italian organic honeys from different productive areas in relation to potential environmental pollution. Chemosphere 154: 482-490.

14.J Lemos, MC Sampedro, An Ariño, An Ortiz, RJ Barrio (2016) Risk assessment of exposure to pesticides through dietary intake of vegetables typical of the Mediterranean diet in the Basque Country. Journal of Food Composition and Analysis 49: 35-41.

15. L Quijano, V Yusà, G Font, O Pardo (2016) Chronic cumulative risk assessment of the exposure to organophosphorus, carbamate and pyrethroid and pyrethrin pesticides through fruit and vegetables consumption in the region of Valencia (Spain). Food Chem Toxicol 89: $39-46$.

16. MAZ Chowdhurya, A Fakhruddin, MN Islam, M Moniruzzaman, SH Gan, et al. (2013) Detection of the residues of nineteen pesticides in fresh vegetable samples using gas chromatography mass spectrometry. Food Control 34(2): 457-465.

17. ANVISA (Agência Nacional de Vigilância Sanitária) (2013) Programa de Análise de Resíduos de Agrotóxicos em Alimentos - PARA. Relatório de atividades de 2011 e 2012.

18. ANVISA (Agência Nacional de Vigilância Sanitária) (2014) Programa de Análise de Resíduos de Agrotóxicos em Alimentos - PARA. Relatório complementar relativo à segunda etapa das análises de amostras coletadas em 2012

19. BH Zainudin, S Salleh, R Mohamed, KC Yap, H Muhamad (2015) Development, validation and determination of multiclass pesticide residues in cocoa beans using gas chromatography and liquid chromatography tandem mass spectrometry. Food Chem 172(1): 585595.

20. MA Farajzadeh, MRA Mogaddam, SR Aghdam, N Nouri, M Bamorrowat (2016) Application of elevated temperature-dispersive liquid-liquid microextraction for determination of organophosphorus pesticides residues in aqueous samples followed by gas chromatography-flame ionization detection. Food Chem 212(1): 198-204. 
21. AG Frenich, R Romero-González, M Mar Aguilera-Luiz (2014) Comprehensive analysis of toxics (pesticides, veterinary drugs and mycotoxins) in food by UHPLC- MS. TrAC Trends in Analytical Chemistry 63: $158-169$

22. Ż Bargańska, M Ślebioda, J Namieśnik (2014) Determination of pesticide residues in honeybees using modified QUEChERS sample work-up and liquid chromatography-tandem mass spectrometry. Molecules 19(3): 2911-2924.

23. JM Gerage, APG Meira, MV Silva (2017) Food and nutrition security: pesticide residues in food. Nutrire 42(1): 1-9.

24. MC Chiaradia, CH Collins, ICSF Jardim (2008) 0 estado da arte da cromatografia associada à espectrometria de massas acoplada à espectrometria de massas na análise de compostos tóxicos em alimentos. Química Nova 31(3): 623-636.

25. C Benbrook, B Baker (2014) Perspective on dietary risk assessment of pesticide residues in organic food. Sustainability 6(6): 3552-3570.

26. R Yu, Q Liu, J Liu, Q Wang, Y Wang (2016) Concentrations of organophosphorus pesticides in fresh vegetables and related human health risk assessment in Changchun, Northeast China. Food Control 60: 353-360.

27. NA Jardim, ED Caldas (2012) Brazilian monitoring programs for pesticide residues in food-Results from 2001 to 2010. Food Control 25(2): 607-616.

28. JS Sousa, RC Castro, GA Andrade, CG Lima, LK Lima, et al. (2013) Evaluation of an analytical methodology using QuEChERS and GC-SQ/ MS for the investigation of the level of pesticide residues in Brazilian melons. Food Chemistry 141(3): 2675-2681.

29. Instrução Normativa ${ }^{\circ} 11$, de 25 de julho de 2016. Brasília, DF, 27 julho 2016. Seção, Brasil (1): 02.

30. (2019) ANVISA (Agência Nacional de Vigilância Sanitária) Monografias de agrotóxicos.

31. (2018) MAPA (Ministério da Agricultura Pecuária e Abastecimento) Regularização da Produção Orgânica.

32. MG López, RJ Fussell, SL Stead, D Roberts, M McCullagh, et al. (2014) Evaluation and validation of an accurate mass screening method for the analysis of pesticides in fruits and vegetables using liquid chromatography-quadrupole-time of flight-mass spectrometry with automated detection. Journal of Chromatography A 1373(19): 40-50.

33.S Grimalt, P Dehouck (2016) Review of analytical methods for the determination of pesticide residues in grapes. J Chromatogr A 1433(12): $1-23$.

34. PGA Barbosa, FICC Martins, LK Lima, MAL Milhome, RM Cavalcante, et al. (2018) Statistical analysis for quality adjustment of the analytical curve for determination of pesticide multiresidue in pineapple samples. Food Analytical Methods 11(2): 466-478.

35. B Łozowicka, E Rutkowska, M Jankowska (2017) Influence of QuEChERS modifications on recovery and matrix effect during the multi-residue pesticide analysis in soil by GC/MS/MS and GC/ECD/NPD. Environmental Science and Pollution Research 24(8): 7124-7138.

36. A Srivastava, S Rai, AK Sonker, K Karsauliya, CP Pandey, et al. (2017) Simultaneous determination of multiclass pesticide residues in human plasma using a mini QuEChERS method. Anal Bioanal Chem 409(15): 3757-3765.

37. ANVISA (Agência Nacional de Vigilância Sanitária) (2016) Programa de Análise de Resíduos de Agrotóxicos em Alimentos-PARA. Relatório das análises de amostras monitoradas no período de 2013 a 2015.

38. OD Prestes, MB Adaime, R Zanella (2011) QuEChERS: possibilidades e tendências no preparo de amostra para determinação multirresíduo de pesticidas em alimentos. Scientia Chromatographica 3(1): 51-64.

39. LHP Bastos, AV Gouvêa, F Málaga, MHW Cardoso, SD Jacob, et al. (2012) Implementação de método analítico para determinação de resíduos de organofosforados em leite por cromatografia a gás com detector fotométrico de chama. Quím Nova 35(8): 1657-1663.

40. J Kowalski, S Lupo, J Cochran (2014) Mitigating Matrix Effects: Examination of Dilution, QuEChERS, and Calibration Strategies for LCMS/MS Analysis of Pesticide Residues in Diverse Food Types. Restek $1-22$.

41. T Tuzimski, T Rejczak (2016) Application of HPLC-DAD after SPE/ QuEChERS with ZrO2-based sorbent in d-SPE clean-up step for pesticide analysis in edible oils. Food Chem 190(1): 71-79.

42. I Machado, N Gérez, M Pistón, H Heinzen, MV Cesio (2017) Determination of pesticide residues in globe artichoke leaves and fruits by GC-MS and LC-MS/MS using the same QuEChERS procedure. Food Chem 227(15): 227-236.

43. 0 Golge, B Kabak (2015) Determination of 115 pesticide residues in oranges by high-performance liquid chromatography-triple-quadrupole mass spectrometry in combination with QuEChERS method. Journal of Food Composition and Analysis 41: 86-97.

44. SA Morrison, KK Sieve, RE Ratajczak, RB Bringolf, JB Belden (2016) Simultaneous extraction and cleanup of high-lipid organs from white sturgeon (Acipenser transmontanus) for multiple legacy and emerging organic contaminants using QuEChERS sample preparation. Talanta 146: $16-22$

45. A Lozano, B Kiedrowska, J Scholten, M Kroon, A Kok, et al. (2016) Miniaturisation and optimisation of the Dutch mini-Luke extraction method for implementation in the routine multi-residue analysis of pesticides in fruits and vegetables. Food Chem 192(1): 668-681.

46. Y Xu, N Song, Q Zhang, J Liu, G Chen, et al. (2017) A strategy for the evaluation of an analytical approach for selected pesticide residues in complex agricultural product matrices - A case study of leek. Food Chem 221(15): 205-213.

47. REO Barriga, WAZ Cuba, VL Tornisielo, FZ Vilca (2016) Determination of organochlorine pesticides in organic quinoa grains (Chenopodium quinoa Willd.) by GC- $\mu$ ECD, using the QuEChERS method. Revista de Investigaciones Altoandinas - Journal of High Andean Research 18(1): 19-26.

48. S Rai, AK Singh, A Srivastava, S Yadav, MH Siddiqui, et al. (2016) Comparative evaluation of QuEChERS method coupled to DLLME extraction for the analysis of multiresidue pesticides in vegetables and fruits by gas chromatography-mass spectrometry. Food Analytical Methods 9(9): 2656-2669.

49. YJ Lee, MM Rahman, AA El-Aty, JH Choi, HS Chung, et al. (2016) Detection of three herbicide, and one metabolite, residues in brown rice and rice straw using various versions of the QuEChERS method and liquid chromatography-tandem mass spectrometry. Food Chem 210(1): 442450.

50. TM Rizzetti, M Kemmerich, ML Martins, OD Prestes, MB Adaime, et al. (2016) Optimization of a QuEChERS based method by means of central composite design for pesticide multiresidue determination in orange juice by UHPLC-MS/MS. Food Chem 196(1): 25-33.

51. M Anastassiades, SJ Lehotay, D Štajnbaher, FJ Schenck (2003) Fast and easy multiresidue method employing acetonitrile extraction/ partitioning and "dispersive solid-phase extraction" for the determination of pesticide residues in produce. J AOAC Int 86(2): 412431.

52. J Li, D Li, J Wu, J Qin, J Hu, et al. (2017) Simultaneous determination of 35 ultra- trace level organophosphorus pesticide residues in Sanjie Zhentong capsules of traditional Chinese medicine using ultra highperformance liquid chromatography with tandem mass spectrometry. Journal of Separation Science 40(4): 999-1009.

53. XC Wang, B Shu, S Li, ZG Yang, B Qiu (2017) QuEChERS followed by dispersive liquid-liquid microextraction based on solidification of floating organic droplet method for organochlorine pesticides analysis in fish. Talanta 162(1): 90-97. 
54. 0 Golge, B Kabak (2015) Evaluation of QuEChERS sample preparation and liquid chromatography-triple-quadrupole mass spectrometry method for the determination of 109 pesticide residues in tomatoes. Food Chem 176(1): 319-332.

55. G Giacinti, C Raynaud, S Capblancq, V Simon (2016) Matrix-matching as an improvement strategy for the detection of pesticide residues. J Food Sci, 81(5): T1342-T1350.

56. J Hong, A Kawashima, M Okamoto, K Kanetsuki, T Makino, et al. (2016) Fundamental study of a novel membrane filtration cleanup method for pesticide analysis in agricultural products. Food Control 64: 1-9.

57. YF Li, LQ Qiao, FW Li, Y Ding, ZJ Yang, et al. (2014) Determination of multiple pesticides in fruits and vegetables using a modified quick, easy, cheap, effective, rugged and safe method with magnetic nanoparticles and gas chromatography tandem mass spectrometry. J Chromatogr A 1361: 77-87.

58. MÁ González-Curbelo, B Socas-Rodríguez, M Herrero, A Herrera-Herrera, J Hernández-Borges (2017) Dissipation kinetics of organophosphorus pesticides in milled toasted maize and wheat flour (gofio) during storage. Food Chem 229(15): 854-859.

59. Z He, L Wang, Y Peng, M Luo, W Wang, et al. (2015) Multiresidue analysis of over 200 pesticides in cereals using a QuEChERS and gas chromatography-tandem mass spectrometry-based method. Food Chem 169: 372-380.

60. A Stachniuk, E Fornal (2016) Liquid chromatography-mass spectrometry in the analysis of pesticide residues in food. Food Analytical Methods $9(6): 1654-1665$

61. D Oshita, ICSF Jardim (2012) Morango: uma preocupação alimentar, ambiental e sanitária, monitorado por cromatografia líquida moderna. Scientia Chromatographica 4(1): 52-76.

62. NM Brito, OP Amarante Júnior, L Polese, TCR Santos, ML Ribeiro (2002) Avaliação da exatidão e da precisão de métodos de análise de resíduos de agrotóxicos mediante ensaios de recuperação. Pesticidas: Revista de Ecotoxicologia e Meio Ambiente 12: 155-168.

63. AM Rebelo, MD Dolzan, M Heller, FC Deschamps, G Abate, et al. (2016) Simultaneous determination of herbicides in rice by QuECHERS and LC-MS/MS using matrix-matched calibration. Journal of the Brazilian Chemical Society 27(1): 186-193

64.S Walorczyk (2014) Validation and use of a QuEChERS-based gas chromatographic-tandem mass spectrometric method for multiresidue pesticide analysis in blackcurrants including studies of matrix effects and estimation of measurement uncertainty. Talanta 120: 106-113.

65. RKS Fermam, AMDS Antunes (2009) Uso de defensivos agrícolas, limites máximos de resíduos e impacto no comércio internacional: estudo de caso. Revista de Economia e Agronegócio/Brazilian Review of Economics and Agribusiness 7(2): 197-214.

66. SCN Queiroz, VL Ferracini, MA Rosa (2012) Validação de método multirresíduo para determinação de agrotóxicos em alimentos empregando QuEChERS e UPLC- MS/MS. Química Nova 35(1): 185-192.

67. Food Safety Brazil (2018) Como consultar os agrotóxicos que podem ser utilizados nosa limentose quaisos limites máximos.

68. MTB Dubugras, E Pérez-Gutiérrez (2008) Perspectiva sobre an análise de risco na segurança dos alimentos. Curso de sensibilização. Rio de Janeiro: Área de Vigilância Sanitária, Prevenção e Controle de Doenças - OPAS/OMS.

69. (2019) Codex Alimentarius. Pesticide Index.

70. (2019) EC (European Commission). EU Pesticides database.

71. (2019) EPA (United States Environmental Protection Agency) Pesticides.

72. Gerage JM (2016) Exposição aos resíduos de agrotóxicos por meio do consumo alimentar da população brasileira. f Dissertação (Mestrado em Ciências) Universidade de São Paulo, Piracicaba.

73. APG Meira, MV Silva (2019) Resíduos de agrotóxicos potencialmente contidos na dieta habitual de escolares. Segurança Alimentar e Nutricional 26: e019021- e019021.

74. M Słowik-Borowiec (2015) Validation of a QuEChERS-based gas chromatographic method for multiresidue pesticide analysis in fresh peppermint including studies of matrix effects. Food Analytical Methods 8(6): 1413-1424.

75. ANVISA (Agência Nacional de Vigilância Sanitária). Programa de Análise de Resíduos de Agrotóxicos em Alimentos - PARA. Relatório de atividades de 2010, 2011

76. (2006) ANVISA (Agência Nacional de Vigilância Sanitária). Resíduos de agrotóxicos em alimentos. Revista Saúde Pública 40: 361-363.

77. (2009) ANVISA (Agência Nacional de Vigilância Sanitária). Programa de Análise de Resíduos de Agrotóxicos em Alimentos - PARA. Nota Técnica para divulgação dos resultados do PARA de 2008.

78. JG Lorenz, LL Costa, EA Suchara, ES Sant'Anna (2014) Multivariate optimization of the QuEChERS-GC-ECD method and pesticide investigation residues in apples, strawberries, and tomatoes produced in Brazilian south. Journal of the Brazilian Chemical Society 25(9): 15831591.

79. ANVISA (Agência Nacional de Vigilância Sanitária) (2010) Programa de Análise de Resíduos de Agrotóxicos em Alimentos-PARA. Relatório de atividades de 2009. 